\title{
Obscenidad y explicitud: dos formas de acercarse a la literatura de la violencia*
}

\author{
Alfonso Valencia ${ }^{1}$ \\ Universidad Veracruzana (México)
}

\begin{abstract}
Resumen
Este artículo explora tendencias contrapuestas en la reacción crítica a la literatura de violencia durante el auge mediático del narcotráfico en México: la condena estética de la "inmadurez" del género y la celebración alternativa de la puesta en escena de víctimas $\mathrm{y}$ victimarios. Este trabajo analiza algunas generalidades de Trabajos del Reino, de Yurí Herrera, y de Las tierras arrasadas, de Emiliano Monge, desde la dicotomía obscenidad / explicitud.
\end{abstract}

Palabras clave: obscenidad, narcoliteratura, estetización de la violencia.

\begin{abstract}
This article explores competing trends in the critical reaction to the literature of violence during the mediatic rise of drug trafficking in Mexico: the aesthetic condemnation of the "immaturity" of the genre and the alternate celebration of the onscenity (being-on-scene) of victims and victimizers. This paper analyzes some generalities of Yurí Herrera's Trabajos del Reino and Emiliano Monge's Las tierras arrasadas from the perspective of the dichotomy obscenity / onscenity.
\end{abstract}

Keywords: obscenity / onscenity, narcoliterature, aesthetics of violence.

La primera parte de este trabajo cuestiona la crítica que niega el presente a la llamada narcoliteratura por cuestiones como la voracidad del mercado o la falta de una obra "mayor", condenándola al futuro. Surge de la reflexión de dos ideas, digamos antagónicas, respecto al fenómeno de la literatura de la violencia en el contexto del triunfo mediático del narcotráfico en Latinoamérica ${ }^{2}$. La primera de estas

\footnotetext{
* Obscenity and onscenity: approaching the literature of violence

1 Candidato a Doctor en Literatura Hispanoamericana, Universidad Veracruzana, México. Correo electrónico: valencia.alphonse@gmail.com

2 Estas ideas fueron publicadas en un "Mano mano", titulado "Narcoliteratura", en la revista Tierra Adentro número 222, correspondiente al bimestre mayo-junio de 2017. Consta de dos textos: "La narconovela aún (no) existe", de Geney Beltrán Félix; y "Aquellos", de Orfa Alarcón.
} 
consideraciones, expuesta por Geney Beltrán Félix, se trata de una defensa desde un estilo de estética insatisfecha que espera la novela del narcotráfico que sirva para medir a todas sus demás congéneres: una condena de, según el autor,

el simplismo argumental de las obras que responden, no a una necesidad histórica o estética, sino comercial. Esta postura -que recuerda a la de Rafael Lemus en la fundacional polémica con Eduardo Antonio Parra protagonizada en Letras Libres en $2005{ }^{3}$ desplaza la manifestación literaria de la llamada narcoliteratura a un idílico futuro en el que podamos evaluar sus dimensiones objetivamente, cuando ya no estén ni los muertos ni las editoriales aprovechen para saturar el mercado. La segunda perspectiva es de Orfa Alarcón, y desde ella se defiende la necesidad de estas manifestaciones literarias en cuanto dan voz y ponen en escena tanto a víctimas como a victimarios, es decir, al otro y su experiencia negada en nuestra cotidianeidad de espectadores de la atrocidad ${ }^{4}$.

En la segunda parte, enfrento dos modos distintos de narrar la violencia. Su origen es una idea sencilla: la intuitiva oposición entre una violencia que sucede fuera de escena, es decir, obscena ${ }^{5}$-del griego obs-scaena: literalmente, fuera de escena: lejos de las miradas (Barba y Montes: 81)- y otra explícita que se manifiesta de forma hiperbólica, hiperabundante. ${ }^{6}$ Los autores enfrentados son los mexicanos Yuri Herrera y Emiliano Monge. La reflexión es impulsada por lo expuesto en la primera parte: la necesidad de anali-

3 En septiembre de 2005, Rafael Lemus publicó el artículo "Balas de salva" (un juego de palabras que evoca la novela Balas de plata del sinaloense Élmer Mendoza), acusando a toda una camada de escritores norteños de estar erigiendo una literatura intrascendente alrededor del cliché y las fórmulas de algo llamado "narcoliteratura", que, además, respondía a un ímpetu editorial que publicaba lo que fuera de un tema de moda. A saber: a Eduardo Antonio Parra, Élmer Mendoza y Federico Campbell, entre otros. La respuesta de Parra apareció en la misma revista bajo el título "Norte, narcotráfico y literatura", un mes después.

4 En esta primera parte, de manera secundaria, también se enfrentan dos formas de presentación de la crítica. Para eso, en algún momento, me sirvo como ejemplo del prólogo que Junot Díaz escribió para The Best American Short Stories 2016, editado en 2017.

5 Los conceptos originales obs-scenity / on-scenity fueron propuestos por Linda Williams en su análisis fundacional de los estudios sobre el porno. Se trata, a grandes rasgos, de un proceso en el que discursos "prohibidos" paulatinamente van ganando terreno en espacios de exhibición permitidos. Aquí parto de la lectura que del trabajo de Williams hacen Andrés Barba y Javier Montes en La ceremonia del porno.

6 Cuando escribo "realidad hiperabundante", me refiero a esa que es imposible de ser convertida en una ficción literaria convincente (Revueltas, 1978: 18), y que se opone al lado moridor de la realidad, o sea, en el que se la aprehende, sujeta y se somete a leyes. Estas propuestas aparecen en el prólogo que, en 1961, José Revueltas escribió para Los muros de agua. 
zar la literatura de la violencia desde el presente y en atención a la obliteración de víctimas y victimarios; así como por la necesidad de explicar las violencias obsceno / explícitas a partir de dos autores importantes para comprender el fenómeno de la ficcionalización y estetización de la violencia en la literatura mexicana de las primeras décadas del siglo XXI.

¿Cómo condenar la intoxicación de realidad de la literatura mexicana contemporánea? ¿Desde qué punto -inexistente y fuera del mundopodría sancionarse el exceso de realidad en lo que hoy se escribe, circundado por la atrocidad y la deshumanización totales? ¿Cómo, con la mano en la cintura condenar la "estética deficiente" de una "tendencia" que responde al mercado, a los "números negros del gerente de ventas de una editorial”? (Beltrán Félix, 2017).

En un extremo existe una crítica paladina de la estética, policía de lo que sea que signifique la novedad, exigente de una "evolución del estilo", de una superación del oportunismo editorial y del revolcamiento de novelas de aventuras, policiacas o de folletín, y expectante del "Pedro Páramo, del Gran sertón, de la vida de la droga" (Beltrán Félix, 2017). En el otro extremo late, despacio, una crítica que se centra en el otro: en la experiencia ya de la víctima, ya del victimario; nunca en la nuestra, que podrá ser condescendiente, fanática o indiferente, pero siempre privilegiada.

No es que estén "enfrentados" estos dos modos de acercamiento, pero digamos que, en una esquina se atrincheran quienes son incapaces de ver la novedad en el fenómeno actual de la literatura de la violencia. Éstos afirman, por ejemplo, que no hay nada nuevo en Pérez Reverte, Élmer Mendoza o Bernardo Fernández (Beltrán Félix, 2017). Que en ellos y todos los otros no hay nada más que técnica convencional. Entiéndase: el resultado de una fórmula, el seguimiento de una serie de pasos que incluyen botudos, balazos y una chica empoderada. Desde esa esquina se condena la literatura de la violencia mediante una operación que me hubiese gustado saber obsoleta: la condena romántica al todo lo pasado fue mejor. Desde esa esquina, se nombran las manifestaciones literarias con algún concepto, se definen y cuelgan de la rama de alguna tradición para observarlas como parte de un fenómeno que no ha parado de evolucionar, desde una perspectiva falsamente objetiva: la ilusión del distanciamiento crítico que, ante la atrocidad, mira hacia otro lado, fiel a su desapasionada objetividad y deshumanizado juicio estético. Desde esa es- 
quina, se espera al futuro, un momento ideal que nunca es presente, para analizar el presente: "es natural que se requiera la distancia que sólo da el tiempo para poner en perspectiva a través de una obra ambiciosa y madura un fenómeno en el que la sociedad mexicana sigue inmerso". Quienes desde allá escriben, afirman que estamos rodeados de textitos "olvidables, epigonales, blandengues" (Beltrán Félix, 2017), refugiados, en el mejor de los casos, en "una versión tardía del realismo" y en "lo lírico a manera de consuelo" (Domínguez Michael, 2017), en un periodismo paródico que intenta explicar la barbarie. En esa esquina, digamos estetizante, inmanente, erudita, se atan las obras del presente a dos extremos insuperables: el pasado -mediante una insistencia en la espiralidad de las formas estéticas y un eterno retorno al origen, ya sea clásico en el sentido estricto (Apuleyo es la deslumbrante maravilla -y no es que no lo sea, sino que lo vuelve un punto insuperable, como si la literatura pudiera medirse con una vara), ya sea fundador: el origen como modelo, aunque sólo sea un sesgo consensuado. Es decir: no se puede entender la narcoliteratura sin, digamos, Los bandidos de Río Frío; aunque, sin demeritar a Paynó, sí se pueda. Esa condena al pasado, automáticamente se convierte en una condena al futuro: hay que esperar, entonces, el juicio del tiempo para mirar el auténtico valor de una obra, como si el problema metodológico fuera, o bien que no hay herramientas en el presente para aproximarnos a estas manifestaciones literarias, o que el poder poético surge con el paso del tiempo y no de la obra misma. Digamos que, desde esa esquina, el presente es inexistente. Allá pesa la voz de una autoridad que intenta explicar el ¿por qué se escribe? de las nuevas generaciones como si todas las juventudes fueran una misma, y el tiempo y su experiencia una sola, inmutable. Desde allá, cualquier experimentalismo se reduce a Mallarmé, y cualquier atrevimiento estético, a la influencia europeizante de las vanguardias. No hay sorpresas más que en el archivo y sólo entonces puede encontrarse el brillo del temprano arriesgue, que se entiende sólo con la "madurez" del autor, lo que sea que eso signifique, y en la retrospectiva que todo lo aquilata.

En la esquina contraria se encuentra otra crítica que, si bien no es diametralmente opuesta a la que acabo de describir, se centra en el presente y desde ahí viaja al pasado para arrojar luz al futuro. La mirada desde esta esquina nace de la fascinación y no niega la subjetividad de esa perspectiva: al contrario, la vuelve una herramienta y un medio. La condena estética se abre a una perspectiva global que admite lecturas múltiples, desde distintas intersecciones disciplinarias. Desde aquí, la obra literaria se convierte en un centro gravitacional en el presente, y el acercamiento a ella se realiza mediante un sesgo empático que abre la puerta a lecturas 
e interpretaciones que, más que explicar, siembran dudas, cierran puertas, como la literatura misma. Desde aquí se llega a conclusiones que, desde la otra esquina, usualmente son consideradas "faltas de rigor", aunque éste en realidad exista, pero sea sacrificado en nombre de la originalidad y la creatividad. ${ }^{7}$ Aquí el rigor muta en una estructura empática: con lo leído, con el presente -en el sentido de la "experiencia del presente", ausente en la otra esquina, claro- y con el lector. Desde aquí, la literatura de la violencia es un modo de hacer visible al otro. Superado el factor estético (o, en todo caso, sublimado a un nivel con la experiencia), se entienden estas escrituras como un mecanismo para poner en nuestro campo visual privilegiado y aséptico, la terrible experiencia de la víctima, del victimario. Y si acaso nuestra mirada estuviera ya marcada por cualquiera de esas atrocidades (es decir, ser víctima o ser victimario), proponer la fascinación de la trascendencia. Desde acá, la novedad que antes le fue negada a Pérez Reverte, aparece en una forma ajena a la sistemática que llena publicaciones "eruditas": "Es conocida la fascinación del Chapo por Kate del Castillo, quien vio en ella a la mismísima Reina del Sur. Ellos quieren verse retratados, inmortalizados, nosotros queremos saber más de ellos. Fascinación de ida y vuelta" (Alarcón, 2017). Desde acá, se infiere que las literaturas de la violencia son necesarias, y que más allá de la condena a una estética explícita y repetitiva, es necesario analizarlas ahora: "La creación de un narcocorrido, una narconovela, una narcoserie, no implica el riesgo de muerte que trae consigo el desenmascaramiento periodístico del crimen, porque mientras el compromiso del periodista es con la verdad, el compromiso del escritor es con la ficción, y cualquier cosa puede llevar esa bandera" (Alarcón, 2017). Así, acá conviven Sin tetas no hay paraíso, Los minutos negros o el nuevo capítulo de Narcos. En esta esquina se entiende que la literatura sirve para hablar de los otros, "preservando una memoria que mancha pero que debe mencionarse" (Alarcón, 2017). Y se hace no para perdonar, justificar ni aceptar, como pensarían los teóricos de la memoria y el testimonio, sino para "lid-

\footnotetext{
7 Desde acá, por ejemplo, se propone, no se afirma: "Si la novela es nuestra forma literaria favorita, esa sobre la cual colocamos nuestros laureles literarios, si la novela es, digamos, nuestro Jaime Lannister, entonces el cuento es nuestro Tyrion: el hermano menor desdeñado, el eterno subestimado". Pero esto no se propone en un sentido donde lo pop emerge sólo por emerger: o sea, en el terreno de la obviedad: la novela es larga y el cuento, corto; sino con un rigor de pensamiento que llega a revelaciones interesantes: "los cuentos, después de todo, son cortos, justo como nuestros tiempos humanos. Narrativamente hablando, todos nosotros somos Tyrion. Comparado con la novela, el cuento golpea como la vida y termina inmisericorde y abruptamente, como ella. Justo cuando te acomodas en el universo de un cuento, la narración empieza a cerrarse, expulsándote de su abrazo, usualmente para siempre" (Díaz, 2017, traducción mía).
} 
iar con aquello", es decir con la violencia, con la muerte, con el desmembramiento social y corporal; para "lidiar con aquellos", es decir, los otros: los operarios del crimen, de la decapitación, de la invasión sangrienta del espacio público: y también de los otros "otros", las víctimas: pixeleadas en noticiarios, desconocidas, innombrables y anónimas. "La ficción nos ayuda a entender que aquellos no son tan lejanos, que los otros no son tan aquellos" (Alarcón, 2017). Desde esta esquina, la propuesta de lectura va más allá del regodeo intelectual: una vez saldado el compromiso del rigor y la "objetividad", se propone una lectura simultánea del presente y de sus obras. Explicación recíproca. Consideración de la memoria. Compromiso con el presente y conexión.

\section{II}

Desde acá me gustaría hablar de dos autores que considero importantes no sólo para comprender nuestra actualidad literaria, sino nuestro presente: Yuri Herrera y Emiliano Monge. De algún modo, ambos escriben desde este innegable presente que es pura atrocidad rampante. De algún modo, ambos apuntan a las consecuencias de un fenómeno que pareciera formar parte de un "presente eternizado", de un poder omnipresente y omnipotente. Y digamos, también, que, de algún modo, las propuestas de ambos desdeñan una explicación del origen para llevarnos al centro-presente del fenómeno de la violencia. Ambos "desbordan de realidad", despertando el interés de quienes se preocupan por el problema de la representación y de los que vienen desde el realismo decimonónico tardío a decirnos que no hay otra cosa más que la reelaboración de formas discursivas. Ambos, éxitos de ventas, despiertan la sospecha instintiva de quienes, aparentemente, no se dejan sorprender por el brillo de la novedad, aunque éste sea, a todas luces, auténtico. Ambos animan el desdén y la "cautela metodológica" de quienes prefieren la acción dorada del tiempo y la distancia desapasionada. En ambos, la violencia y sus tensiones subrepticias y superficiales mantienen sus narraciones en densas calmas, en latencias constantes. En ambos, la atrocidad estalla.

Antes de seguir, reduzcamos las opciones de escribir la violencia (ficcionalmente, claro) a dos, obedeciendo, más o menos, a un canon clásico. Tendríamos, entonces, la violencia obscena y la violencia explícita. Digo violencia obscena en el sentido de lo que sucede fuera de escena, refiriéndome a las representaciones trágicas clásicas. En ellas, la muerte está presente, la sangre, pero negada a la vista del espectador. Se escuchan los gritos de dolor pero nunca 
vemos nada de manera explícita. Pongamos como ejemplo el asesinato de Clitemnestra en Electra, de Eurípides: sucede dentro de la casa, es decir, se sugiere que el público no ve la sangrienta escena, sólo escucha el clamor de la madre a punto de ser asesinada: "Hijos, por los dioses, no matéis a vuestra madre; ay, ay de mí", y al coro: “¿yes los gritos bajo el techo?”, y luego: "También yo gimo por la que ha muerto a manos de sus hijos". Clitemnestra y Orestes salen manchados de sangre -signo de la tragedia- y se van: "Mas helos aquí que ponen su pie fuera de la casa teñidos con la sangre reciente de su madre" (vv. 1165).

Lo mismo pasa en Edipo Rey, de Sófocles: el mensajero es quien narra el violento desenlace de Edipo: "Las pupilas ensangrentadas teñían las mejillas y no destilaban gotas chorreantes de sangre, sino que todo se mojaba con una negra lluvia y granizada de sangre" (vv.1275): así se enteran el coro, el corifeo y el público del autosacrificio del protagonista. Lo que sucede fuera de la escena es lo violento, y la palabra basta para recrearlo: lo que está vedado al ojo no lo está al oído.

Esta forma de representar la violencia podríamos oponerla a la explicitud sangrienta de la épica clásica, en la que existe un regodeo en el triunfo del metal sobre la carne, la sangre negra, la ceguera de los personajes ante la muerte. Recordemos la primera batalla de la Ilíada, tras el desembarco aqueo en costas troyanas: "Cuando los ejércitos llegaron a juntarse, chocaron entre sí los escudos, las lanzas y el valor de los hombres armados [...] Allí se oían simultáneamente los lamentos de los moribundos y los gritos jactanciosos de los matadores, y la tierra manaba sangre...”; y más adelante, la descripción de la primera muerte perpetrada por Antíloco: "hirióle en la cimera del penachudo casco, y la broncínea lanza, clavándose en la frente atravesó el hueso, las tinieblas cubrieron los ojos del guerrero y éste cayó como una torre en el duro combate". Más adelante, Leuco es herido de muerte, y Odiseo, "irritado por la muerte de su compañero, le envasó [al asesino] la lanza, cuya broncínea punta le entró por una sien y le salió por la otra". Casi al final de la reyerta, Diores Amarincida es herido por una piedra que le rompió el tobillo derecho, y mientras en el suelo "tendía los brazos a sus camaradas", Píroo Imbrásida "acudió presuroso e hirióle nuevamente con la lanza junto al ombligo; derramáronse los intestinos y las tinieblas velaron los ojos del guerrero" (Rapsodia IV, vv. 446-526).

Entonces, tenemos un estilo obsceno, en cuanto está presente sin estarlo; y otro que muestra de manera evidente. Ambos son terribles, pero los diferencia su intención de explicitud. Se trata de una oposición similar a la Obscenity / Onscenity propuesta por Linda 
Williams (1989) ${ }^{8}$ : la obscenidad como aquellos discursos prohibidos que necesariamente son mostrados fuera de espacios aceptados, y la onscenidad (literalmente: lo que sucede en escena) como aquellos prohibidos que poco a poco van ganando espacio en lo público (permitido) hasta neutralizarse; en un estilo de "negociación permanente que intensifica la conciencia de todos aquellos asuntos que en su día fueron obscenos y que ahora asoman y nos miran emboscados detrás de cada arbusto" (Barba y Montes, 2007: 81-82).

En un extremo está Yuri Herrera, en el otro Emiliano Monge.

La violencia fuera de escena de Herrera sacude a nivel, digamos, estructural, porque se encuentra no en la superficie, sino entre lo dicho. Como en la representación trágica, sólo escuchamos ecos, nos enfrentamos a meras insinuaciones que vuelven a la violencia un estilo de espíritu que late detrás de lo obvio, permeando cada palabra. La violencia para He- rrera es un fantasma. Una fuerza invisible y silenciosa que mantiene la tensión de un universo endeble, existente gracias sólo a esa tensión, que evita que sus habitantes se maten los unos a los otros. En Trabajos del reino (2008), por ejemplo, Yuri Herrera propone abordar el fenómeno del narco en su esencia, no en su consecuencia: hace del poder de la mafia una gran metáfora basada en arquetipos: El Rey y sus súbditos. Arranca el fenómeno del narco de su contexto, elidiendo nombres de lugares y a la mafia misma: la violencia asociada a los cárteles, aunque la sabemos presente, nunca se menciona. No se dice nada, pero se entiende todo:

- Pensé que andaba del otro lado -dijo el Artista.

- Fui y volví, pero no hay nada que sirva, ¿qué van a saber? El Pocho ya ni se paraba por allá, desde que les dio la espalda a aquellos ya nomás hacía negocios de este lado. Es más: él ya de lo único que se encargaba era de conseguirle hembras al Señor, como si le hubieran servido para algo, pero eso -se llevó con torpeza un índice a los labios-, esto, chitón, ¿eh? Ustedes no saben nada... Y yo tampoco sé nada de ustedes. Mejor. Mejor no saber, ahora que todo se va a ir a la chingada (Herrera, 2008: 84).

Por otro lado, la violencia de Emiliano Monge es terrible por cercana: reproduce (o parece hacerlo) las escenas que nos rodean. Su oferta explícita no cede al silencio ni al estratégico ocultamiento que

8 Ver: Williams, Linda. Hard Core: Power, Pleasure, and the "frenzy of the Visible". Berkeley: University of California Press, 1989. 
propone Herrera: es estruendosa. Mientras que Herrera crea un ambiente donde la violencia se respira en todos lados -aunque no suceda nada-, Monge crea una imagen que parece infectada de realidad. Herrera nos mantiene "a las afueras" de un fenómeno que sabemos reconocer gracias a la nota roja, al bombardeo mediático de la tragedia y la sangre, mediante un rodeo del lenguaje, mediante un consciente evitar determinados campos semánticos surgidos de la fuerza de atracción del narco, de las armas, de la muerte, del desmembramiento. Herrera niega el mundo a través del uso de una alegoría (el rey, su reino y sus súbditos) y un ceder al aplastante silencio y a la acción implacable de la palabra en el momento justo. La violencia de los personajes de Herrera es contraria a la objetiva -física- que podría suponerse imprescindible para lograr la espectacularidad del género: sus protagonistas jamás disparan una bala, les basta saber hablar. Así, en sus universos -en las afueras del "reino", en el camino de los migrantes hacia Estados Unidos y en la frontera- la tensión se mantiene entre los operarios de una violencia objetiva concreta (militar, policial) y los que se defienden sólo con la palabra... y triunfan. Ahí, el poderoso lo es porque ejerce la violencia simbólica del miedo, de la amenaza, de la tensión de la violencia física que rodea a los personajes, que existe pero no, que no se manifiesta en términos sangrientos sino que se manifiesta mediante la posibilidad, es decir, pura amenaza, pura tensión. Ante esta forma de ejercer el poder, los protagonistas recurren no al contraataque en los mismos términos de violencia (total o contenida), sino a violentar el universo de la palabra: su arma no es la amenaza, el sinsentido de la violencia por la violencia, sino la argumentación que violenta la estructura lingüística del poderoso: la provocación del descubrimiento de su sinsentido y su equivocación.

Por otro lado, la violencia de Emiliano Monge nos sacude pues se regodea del mundo y sus materiales y sus cuerpos y palabras, las cuales vienen del infierno: tanto del literario -el de Dante, cuyos pasajes se entreveran parafraseados en la narración para darle voz a la experiencia de los migrantes secuestrados y forma a la noche en que se mueven-, tanto del real que experimentan los migrantes víctimas del crimen organizado mexicano -infierno explícito gracias a la inclusión en la narración de testimonios obtenidos de entrevistas a migrantes centroamericanos realizadas por asociaciones de justicia. La violencia de Monge en Las tierras arrasadas (2015) alcanza su punto álgido, su máxima representación hiperbólica no en la ficción, sino en el ceder la voz narrativa al "testimonio": justo cuando el relato pareciera que romperá el pacto de verosimilitud por acercarse a la descripción exagerada de la atrocidad, aparece el testimonio como testigo fiel de que la realidad siempre es más que la ficción, y que, 
tratándose de lo terrible, del espanto, la realidad siempre resulta más atroz que la más retorcida de las imaginaciones. Es, pues, una realidad imaginada donde lo terrible es siempre inaparente (Revueltas, 1978: 10), siempre en la imposibilidad de demostrarse como cierto, real: la realidad que resulta más fantástica que la literatura.

\begin{abstract}
No sé cuántos son exactamente, responde Estela: había en el claro unos setenta... se llevó él como unos veinte... ponle que ahí traigamos pues como cincuenta. ¿Cincuenta?, inquiere el capitán mientras Oigosóloloquequiero cambia un par de marchas y acomete una curva que se asoma peligrosamente al precipicio. Eso dije... debe haber como cincuenta... menos esas que ya se hayan acabado mis muchachos... se les pasa siempre con alguna a ellos la verga (Monge, 2015: 72).
\end{abstract}

La indeterminación del vocabulario, la normalidad con la que se refiere, por saturación y repetición ("setenta", "veinte", "cincuenta") a las víctimas, se suspende para darles voz: quienes se encargan de narrar de primera mano las atrocidades del paso por México hacia el norte, son las propias víctimas: ${ }^{9}$ no hay voz que pueda prestársele a la atrocidad:
Decían que si cooperábamos nos iba a ir mejor... eran mentiras... no paraban nunca... hasta que una ya no pudo... está ésta más rica, dijeron y le dieron por dos la- dos... estaba en su mes y no les importó... todos la viola- ron... luego ella no volvió a pararse... está muerta ya esta puta, dijo uno y se marcharon (Monge, 2015: 72).

Si bien el testimonio no es directo, en cuanto se filtra por la retórica y el ritmo (digamos: el estilo) de la voz narrativa y su predilección por aliteraciones e hipérbatos, hay una intencionalidad por desvincular la voz de las víctimas de la narrativa, centrada en los protagonistas, los victimarios. Esta operación sirve, además, para suspender la narración en otro sentido, justo cuando la atrocidad amenaza con cancelar el pacto de ficcionalidad por hiperabundante, la voz de las víctimas, el aparente testimonio, aparece como testigo de la crueldad

\footnotetext{
9 Aclara el autor en un estilo de epílogo: "Todas las cursivas que aparecen en esta novela pertenecen a La Divina Comedia o son citas tomadas de diversos testimonios de migrantes centroamericanos, a su paso por México, en busca de los Estados Unidos de América" y luego agradece a la Comisión Nacional de los Derechos Humanos, la Comisión Interamericana de Derechos Humanos, Amnistía Internacional, Albergue Hermanos en el Camino, Las Patronas, Casa del Migrante, Sin Fronteras y Casa del Menor Migrante (Monge, 2015: 342).
} 
y salva lo inenarrable de la realidad. Los victimarios hablan, pues son protagonistas no sólo de la historia narrada, sino del mundo:

- Soy la suerte y soy la patria [...] siéntate y observa lo que viene... esto tendrás que hacerlo.

- ¿Qué van a hacer?

- ¡Dirás: qué vamos a hacerles! [...] toca acabar de enmudecerlos... castigarles la cabeza... volverlos ahora nadie (Monge, 2015: 81).

Y justo después, cuando la tortura necesita ser narrada, aparece el testimonio como fiel de la realidad:

No dejaban de gritarnos y pegarnos y orinarnos... no nos dejaban ni hablarnos ni mirarnos... a los que hablaban les pegaban con sus trapos empapados... a los que se buscaban con los ojos se los quemaban con cerillos... luego decían... "ya te moriste"... así estuvimos hasta que nos metieron a los cuartos (Monge, 2015: 81).

Así, la ficción cede ante el horror de la realidad, ante lo inenarrable que sólo puede formularse, aunque mediante una operación retórica, cediendo la voz al otro, poniéndolo en escena.

Si la violencia obscena de Herrera es el limbo -un espacio cercado y contenido por la violencia, atravesado por sus hilos, imposible y existente por ella ${ }^{10}$-, la violencia explícita de Monge es el infierno, el centro del horror. Ambas son caras de una misma hoja: la escritura en una se transparenta en la otra. Ambas están presentes simultáneamente, sin estarlo. Quiero creer que se trata de una literatura siempre despierta, siempre puente entre su universo ficcional y la atrocidad del mundo, siempre despierta por el horror, en conexión permanente con su presente.

10 Se trata del cuartoespacio o fourthspace, propuesta de James Giles en Spaces of Violence: un tipo de espacio que surge del análisis y reflexión de la propuesta de los dos espacios de Lefebvre -el primero, físico; el segundo, mental, y del realimagined place, de Edward Soja, que se suma a la propuesta de Lefebvre como tercero, real e imaginario a la vez, encarnando complejos simbolismos. El cuartoespacio se refiere a uno que, independientemente de su carácter simbólico, real o imaginario, está contenido por la violencia, condenando a sus habitantes a la inacción, negándoles el futuro. 


\section{Bibliografía}

Alarcón, 0. "Aquellos", en Tierra Adentro, mayo-junio (2017). web: http://www.tierraadentro.cultura.gob.mx/narcoliteratura; consultado el 3 de agosto de 2017.

Barba, A. , y J. Montes. La ceremonia del porno. Barcelona: Anagrama, (2007)

Beltrán Félix, G. "La narconovela (aún) no existe”, en Tierra Adentro, mayo-junio 2017. web: http://www.tierraadentro.cultura. gob.mx/narcoliteratura; consultado el 3 de agosto de 2017.

Díaz, J, y H. Pitlor, eds. The Best American Short Stories 2016. Boston: Mariner Books / Houghton Mifflin Harcourt, 2016.

Domínquez M. , C. Novelas abrasivas, en Confabulario, 15 de junio de (2017). web: http://confabulario.eluniversal.com.mx/novelas.abrasivas/; consultado el 2 de noviembre de 2017.

Eurípides. Tragedias II. Madrid: Gredos, (1985).

Giles, J R. The Spaces of Violence. Tuscaloosa: University of Alabama Press, (2006).

Herrera, Y. Trabajos del reino. Cáceres: Periférica, (2008).

Homero. Ilíada. Madrid: Espasa-Calpe, (2000).

Lemus, R. Balas de salva: Notas sobre el narco y la narrativa mexicana. en Letras Libres, septiembre (2005), 39-42.

Monge, E. Las tierras arrasadas. México: Random House, 2015.

Parra, E. A. Norte, narcotráfico y literatura, en Letras Libres, octubre (2005), 60-61.

Revueltas, J. Los muros de agua. México: Ediciones Era, (1978).

Sófocles. Tragedias. Madrid: Gredos, (2006).

Williams, L. Hard Core: Power, Pleasure, and the "Frenzy of the Visible". Berkeley: University of California Press, (1989). 